Relations industrielles

Industrial Relations

\title{
Les ordonnances du salaire minimum
}

Volume 8, numéro 3, juin 1953

URI : https://id.erudit.org/iderudit/1022950ar

DOI : https://doi.org/10.7202/1022950ar

Aller au sommaire du numéro

\section{Éditeur(s)}

Département des relations industrielles de l’Université Laval

\section{ISSN}

0034-379X (imprimé)

1703-8138 (numérique)

Découvrir la revue

Citer ce document

(1953). Les ordonnances du salaire minimum. Relations industrielles / Industrial Relations, 8(3), 337-338. https://doi.org/10.7202/1022950ar

Tous droits réservés @ Département des relations industrielles de l’Université Laval, 1953
Ce document est protégé par la loi sur le droit d'auteur. L’utilisation des services d'Érudit (y compris la reproduction) est assujettie à sa politique d'utilisation que vous pouvez consulter en ligne.

https://apropos.erudit.org/fr/usagers/politique-dutilisation/ 


\section{INFOR.MATIONS}

\section{LES ORDONNANCES DU SALAIRE MINIMUM}

La Commission du salaire minimum vient d'annoncer la revision de ses principales ordonnances: ordonnance no 4, 1942; ordonnance no 3 , revisée, relative aux congés annuels payés; ordonnance no 41 concernant les salariés des corporations publiques; ordonnance no 42 relative aux mécaniciens de machines fixes et aux chaufteurs. La Commission n'a pas renouvelé à leur échéance certaines ordonnances, telles que l'ordonnance no 5 , revisće, relative à l'industrie textile de la soie; l'ordonnance no 8, revisée, concernant l'industrie textile du coton; l'ordonnance no 19 régissant les établissements de fabrication de bas façonnés; l'ordonnance no 37 régissant les verreries à bouteilles. Ces dernières ordonnances étaient devenues périmées en raison du développement du syndicalisme dans ces industries et de la négociation de conventions collectives de travail. Les entreprises antérieurement soumises aux ordonnances abrogées seront dorénavant assujetties à l'ordonnance générale no 4, 1953. 1

\section{Ordonnance no 4, 1953}

L'ordonnance no 4, 1953, de la Commission du salaire minimum régit tous les salariés de la province sujets à la Loi du salaire minimum non autrement couverts par un décret en vertu de la Loi de la convention collective ou une autre réglementation. C'est la principale ordonnance de salaire et de conditions de travail minima; elle étend sa juridiction à plus des deux tiers des salariés de la province quant aux normes de base.

La nouvelle ordonnance remplace l'ordonnance no 4, 1942, dont elle incorpore la majorité des clauses en y apportant parfois plus de précision. Elle présente, cependant, une structure complètement différente. On retrouve dans sa première partie la détermination de son champ d'application; la deuxième contient des règles générales d'application et des définitions. Les taux minima sont groupés dans la troisième partie en sections particulières qui réfèrent à des établissements et entreprises classés non plus d'après leur caractère industriel ou commercial, mais par énumération et assignation à une semaine normale déterminée de 54 ou 60 heures; les autres établissements bénéficient de la semaine normale de base de $\mathbf{4 8}$ heures. On constate un abaissement de la semaine normale dans certaines entreprises, notamment dans l'industrie du bois ouvré. Des établissements, peu nombreux, n'ont aucune semaine normale de travail. La quatrième partie renferme deux autres sections: les hôtels, restaurants et autres entreprises similaires, et les exploitations foncières.

L'ordonnance nc 4, 1953, a adopté le procédé de répétition plutôt que celui de référence, ce qui rend chaque section plus complète et plus cohérente. On y a abandonné, dans la classification des emplois, le mode de répartition des salariés dans des classes de pourcentages; on réfère maintenant à des groupes généraux d'emplois. La limitation du nombre des inexpérimentés a été portée à $20 \%$ du total des salariés de l'établissement, sans toutefois restreindre la durée de la période d'apprentissage.

La province de Québec, pour les fins de cette ordonnance, a été divisée en trois zones au lieu de quatre, et les municipalités qui formaient la zone 4 seront à l'avenir soumises aux conditions de la zone 3 , ce qui entraîne dans les petites localités un relèvement des taux minima allant jusquà $20 \%$. Une augmentation générale de $10 \%$ avait été décrétée le 15 novembre $1952.2 \mathrm{La}$ nouvelle ordonnance

(1) Gazette officielle de Québec des 25 avril et 30 mai 1953.

(2) Gazette officielle de Québec, 15 novembre 1952. 
ne s'appliquera pas uniquement dans les municipalités mais dans tout territoire situé en la province et faisant partie d'un district électoral.

Les salaires minima sont les mêmes pour les salariés masculins et les salariés féminins sans aucune discrimination de sexe ou d'âge.

Signalons également que le registre devra être tenu en la province, à l'établissement de l'employeur et que la période de travail, c'est-à-dire la période de temps pour laquelle le salaire minimum doit être établi et payé est la semaine, sauf dans les hôtels, les restaurants et entreprises similaires où cette période peut être le demi-mois ou le mois normal.

Un index alphabétique s'ajoute à la table générale des matières, ce qui permet de référer plus rapidement et facilement à l'information recherchée et rend l'application et la compréhension de l'ordonnance plus faciles même pour les non-initiés.

\section{Ordonnance no 3 , revisée}

La revision de l'ordonnance no 4 entraînait celle de l'ordonnance no 3, revisée, relative aux congés annuels payés; certaines concordances ont été établies et son champ d'application a été élargi. Quelques dispositions ont été complétées et précisées. Le minimum de congé annuel n'a pas été modifié, non plus que les conditions de détermination et de rémunération du congé.

\section{Ordonnances nos 41 et 42,1953}

Ces deux ordonnances adoptent la structure de l'ordonnance no 4, 1953. Les salaires minima de l'ordonnance no 41,1953 , régissant les salariés des corporations municipales et des corporations scolaires ont été augmentés et portés au niveau de ceux que l'ordonnance générale no 4, 1953, établit; le traitement des instituteurs à l'emploi des commissions scolaires n'a pas été modifié. De plus, les secrétairestrésoriers des municipalités ont bénéficié d'une hausse du salaire minimum. Les taux minima de l'ordonnance no 42,1953, relative aux mécaniciens de machines fixes et aux chauffeurs n'ont pas été modifiés; cependant les taux de la zone III sont maintenant payables dans les petites localités.

Ces modifications législatives marquent une nouvelle étape dans la voie de la simplification et de l'unification de la réglementation du salaire minimum en cette province.

On peut se procurer gratuitement ces documents en s'adressant à la Commission du salaire minimum, 286, rue St-Joseph, Québec, ou 7080, rue Hut'chison, Montréal. 